\title{
Complex Formation and Photochemical Properties of the Crown- Containing Mono- and Bis(styryl)bipyridine Derivatives with Transition Metal Cations
}

\author{
Nikolay E. Shepel, ${ }^{a}$ Olga A. Fedorova, ${ }^{a}$ Elena N. Gulakova, ${ }^{a}$ \\ Gedeminas Jonusauskas, ${ }^{\mathrm{b}}$ and Yuriy V. Fedorov ${ }^{\mathrm{a}}$ \\ ${ }^{a}$ A.N. Nesmeyanov Institute of Organoelement Compounds of Russian Academy of Sciences, 119991 Moscow, Russia \\ ${ }^{\mathrm{b}}$ Centre de Physique Moléculaire Optique et Hertzienne, U.M.R. 5798 UNIVERSITÉ BORDEAUX 1-CNRS, 351, Cours de \\ la Libération - 33405 TALENCE CEDEX, France \\ @Corresponding author E-mail: fedorov@ineos.ac.ru
}

\begin{abstract}
Complex formation of 15-crown-5 ether containing mono- and bis(styryl)bipyridine with transition metal perchlorates was studied. The complex stoichiometry, complex structure and stability constants were determined by electronic spectroscopy. The influence of metal ions on occurrence of E,Z-isomerization was analyzed; the optical characteristics of two isomers were calculated from the photolysis data.
\end{abstract}

Keywords: 15-Crown-5 ether, crown-containing styrylbipyridine, $E$,Z-photoisomerization, complex formation, zinc perchlorate, cadmium perchlorate, mercury perchlorate, cobalt perchlorate, absorption spectroscopy.

\section{Комплексообразование с катионами переходных металлов и фотохимические свойства краунсодержащих моно- и бис(стирия) производных бипиридина}

\author{
Н.Э. Шепель, ${ }^{a}$ О.А. Федорова, ${ }^{a}$ Е.Н. Гулакова, ${ }^{a}$ Г. Йонушаускас, ${ }^{\text {b }}$ Ю.В. Фёдоров ${ }^{a}$ \\ а Учреждение Российской академии наук Институт элементоорганических соединений им. А.Н. Несмеянова РАН, \\ 119991 Москва, Россия \\ 'Центр оптической и электромагнитной молекулярной физики Университета Бордо 1, UMR CNRS 5798,33405 \\ Таланс, Франичия \\ @E-mail:fedorov@ineos.ac.ru
}

\begin{abstract}
Изучено комплексообразование краунсодержаших моно- и бис-(стирил)бипиридинов с перхлоратами переходных и тяжёльх металлов $\left(\mathrm{Zn}^{2+}, \mathrm{Co}^{2+}, \mathrm{Cd}^{2+}, \mathrm{Fe}^{2+}, \mathrm{Hg}^{2+}\right)$, способных к координачии с атомами азота гетероциклического остатка и краун-эфирным фрагментом. Методами электронной спектроскопии определено место координации катиона, стехиометрия образующихся комплексов и рассчитаны константы их устойчивости. Исследовано влияние комплексообразования на протекание E,Z-фотоизомеризации лигандов, определены оптические характеристики Z-изомеров.
\end{abstract}

Ключевые слова: 15-Краун-5-эфир, стирилбипиридин, E,Z-фотоизомеризация, комплексообразование, перхлорат цинка, перхлорат кадмия, перхлорат ртути, перхлорат кобальта, электронная спектроскопия.

\section{Введение}

Для создания супрамолекулярных ансамблей широко используются лиганды, синтезированные на основе производных стирилпиридинов. ${ }^{[1,2]}$ В основе построения таких супрамолекулярных систем лежит способность атома азота гетероциклического соединения образовывать прочные координационные связи с катионами металлов. ${ }^{[3-6]}$ Предполагается, что подобные лиганды и супрамолекулярные ансамбли на их основе могут применяться для создания функциональных систем в мониторинге окружающей среды, медицине и химическом анализе, материалов для фотоники, оптоэлектроники и электрохимического анализа. ${ }^{[7-13]}$ 
Введение ионофорного фрагмента в состав фотохромной молекулы позволяет получить фотохромные краун-соединения нового класса. ${ }^{[14-16]}$ При связывании катионов металлов ионофорным фрагментом фотохромной молекулы происходит существенное изменение оптических характеристик молекулы, что позволяет использовать подобные краун-соеднинения в качестве оптических сенсоров на катионы металлов. С другой стороны, изменения в структуре подобного лиганда в результате фототрансформации фотохромной части молекулы могут оказать существенное влияние на комплексообразующие свойства системы.

\section{Экспериментальная часть}

Растворы перхлоратов металлов приготавливали в ацетонитриле (сорт 1, ос.ч.; УФ поглощение на 200 нм составляет 0.020 о. е./см; содержание воды не более $0.03 \%$, КРИОХРОМ, Россия).

Кристаллогидраты $\mathrm{Hg}\left(\mathrm{ClO}_{4}\right)_{2}, \mathrm{Zn}\left(\mathrm{ClO}_{4}\right)_{2}, \mathrm{Cd}\left(\mathrm{ClO}_{4}\right)_{2}$, использовали без высушивания; концентрацию полученных растворов уточняли титрованием трилоном-Б с индикатором метиленовым оранжевым.

Моногидрат $\mathrm{Fe}\left(\mathrm{ClO}_{4}\right)_{2}$ “Sigma”, США, использовали без дополнительной очистки.

Раствор $\mathrm{HClO}_{4}$ в $\mathrm{MeCN}$ готовился из концентрированной водной хлорной кислоты $(\mathrm{C}=9.84$ моль/л), концентрацию уточняли титрованием $\mathrm{NaOH}$ в автоматическом титраторе “Аквилон” с комбинированным рН электродом.

Приготовление растворов лигандов и все исследования проводили при красном свете.

Электронные спектры поглощения и флуоресценции лигандов и их комплексов записывали в кварцевых кюветах с длиной оптического пути 10 мм при $21^{\circ} \mathrm{C}$, используя ацетонитрил в качестве растворителя. Спектры поглощения регистрировали на спектрофотометре Specord-M40 (Carl Zeiss JENA, DDR), сопряженном с компьютером. Управление спектрофотометром, сбор данных и простейшую математическую обработку спектров проводили с помощью стандартной программы “SPECORD” (версия 2.0, Эталон).

Спектры флуоресценции записывали на спектрофлуориметре «Shimadzu RF-5000».

\section{Квантовые выходы флуоресиенции}

Квантовые выходы флуоресценции свободных лигандов и их комплексов определены при $20 \pm 1^{\circ} \mathrm{C}$ в насыщенных воздухом ацетонитрильных растворах по отношению к сульфату хинина ${ }^{[17]}$ в $0.5 \mathrm{M} \mathrm{H}_{2} \mathrm{SO}_{4}$ в качестве стандарта $\varphi_{\phi л}=0.55 \pm 0.03$. Флуоресценция регистрировалась под прямым углом к возбуждающему пучку света.

Для расчёта квантовых выходов флуоресценции использовалась формула::[18-20]

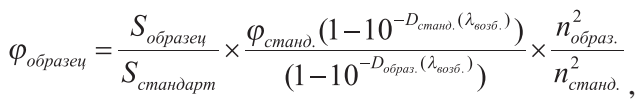

где $S$ - интегральная интенсивность флуоресценции, $D$ оптическая плотность на длине волны возбуждения, $n-$ показатель преломления растворителя, в котором проводились измерения, $\varphi$ - квантовый выход флуоресценции.

\section{Спектры ЯМР}

${ }^{1} \mathrm{H}, \mathrm{COSY}$ и NOESY ЯMP-спектры зарегистрированы на спектрометре Bruker DRX-600 с рабочей частотой 600.22 МГц для протонов, внутренний стандарт - ТМС. Растворитель $\mathrm{CD}_{3} \mathrm{CN}$. Химические сдвиги измеряли с точностью до $0.01 \mathrm{м}$. д., а КССВ с точностью до 0.1 Гц.

\section{Масс-спектрометрия}

Масс-спектры в условиях электрораспыления при атмосферном давлении (ИЭР) регистрировали в режиме полного сканирования масс положительных ионов на тандемном динамическом масс-спектрометре Finnigan LCQ Advantage (США), оборудованном масс-анализатором с октапольной ионной ловушкой, насосом MS Surveyor, автосамплером Surveyor, генератором азота Schmidlin-Lab (Германия) и системой сбора и обработки данных с использованием программы X Calibur версии 1.3 фирмы Finnigan. Температура трансферного капилляра $150^{\circ} \mathrm{C}$, напряжение поля между иглой и противоэлектродом 4.5 кВ. Образцы с концентрацией $10^{-4}$ моль/л в растворе ацетонитрила (если не указано иное) вводили в ионный источник с прямого ввода со скоростью потока 50 мкл/мин через инжектор Reodyne c петлей на 20 мкл.

\section{Расчет констант устойчивости комплексов}

Константы устойчивости комплексов лигандов 1 и 2 с катионами металлов были определены с использованием метода спектрофотометрического титрования при $20 \pm 1^{\circ} \mathrm{C}$. Для спектрофотометрического титрования были приготовлены следующие растворы в ацетонитриле: лиганд $C_{\text {лиг }}=4.3 \cdot 10^{-5}$ моль ग $^{-1}$, перхлорат соответствующего металла $C_{\mathrm{M}}{ }^{\mathrm{n}+}=1 \cdot 10^{-3}$ и $1 \cdot 10^{-1}$ моль Л $^{-1}$. Титрование раствора лиганда раствором перхлората металла проводили следующим способом: известный объём раствора лиганда в ацетонитриле наливали в кварцевую кювету и записывали спектр поглощения. Затем в кювету порциями известного объема добавляли раствор с известной общей концентрацией перхлората металла $\left(C_{\mathrm{M}}^{\mathrm{n}+}\right)$. После каждого добавления записывали спектры поглощения растворов. Титрование прекращали, когда при дальнейшем добавлении соли металла спектры поглощения растворов практически не изменялись, что свидетельствовало о полном комплексообразовании, либо изменения объяснялись лишь разбавлением, что сопровождалось равномерным уменьшением оптической плотности по всему спектру поглощения. Обработку результатов спектрофотометрического титрования и расчет констант устойчивости комплексов проводили с помощью программы «SPECFIT/32", использующей нелинейную оптимизацию методом наименьших квадратов по алгоритму Левенберга-Марквардта.

\section{Оптимизация структур молекул}

Оптимизация структур молекул проводилась в программе MOРАС 2009 21$]$ методом РМ6, со следующим набором параметров: NOSYM PM6 PRECISE CHARGE $=0$ PRNT $=1 \quad$ CYCLES $=10000 \quad$ LARGE $=-1 \quad$ DUMP $=900$ BONDS GNORM $=0.100$.

\section{Обсуждение результатов}

Строение лигандов. В настоящей работе были изучены 15-краун-5-содержащие 4-метил-4'-стирил2,2'-бипиридин $E-1$ и 4,4'-бис(стирил)-2,2'-бипиридин $E, E-2$, молекулярные формулы которых представлены на Схеме 1. 


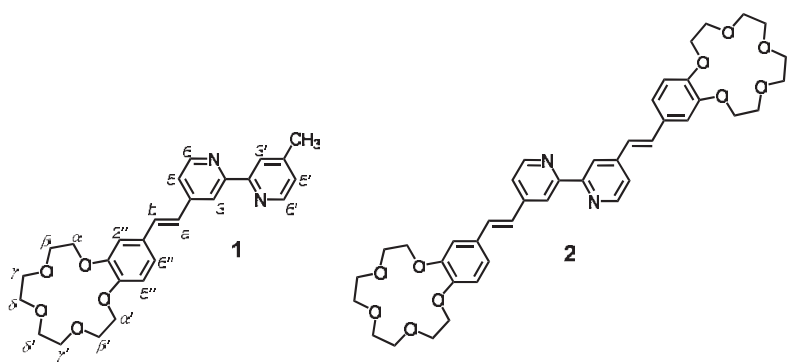

Схема 1.

Данные соединения обладают двумя особенностями: краун-эфирный фрагмент и атомы азота гетероциклических фрагментов являются центрами координации катионов металлов различной природы и протона, а двойная $\mathrm{C}=\mathrm{C}$ связь является антенной, способной улавливать кванты солнечного света. Наличие нескольких центров связывания катионов в молекулах $E, E-2$ и $E$-1 делает их политопными лигандами, перспективными для создания на их основе разнообразных молекулярных ансамблей.

Производные бипиридина 1 и 2 относятся к классу хромо-ионофоров и способны существенно изменять свои фотофизические и фотохимические свойства при комплексообразовании. Хотя примеры краунсодержащих фотохромных соединений известны в литературе, ${ }^{[22-25]}$ закономерности образования супрамолекулярных ансамблей с использованием нескольких центров координации не выявлены, а также не исследовано влияние супрамолекулярной организации на фотофизические и фотохимические свойства систем, не определены перспективы их практического применения.
Строение лигандов $E-1$ и $E, E-2$, полученных по известным методикам, ${ }^{[27]}$ установлено методом ${ }^{1} \mathrm{H}$ ЯМР спектроскопии. ${ }^{[28]}$

В растворе 1 и 2 существуют в виде $E$-изомеров согласно константам спин-спинового взаимодействия олефиновых протонов равных 16.2 Гц (Рисунок 2).

Отсутствие в NOESY спектрах кросс-пиков между H-3 и Н-3' позволяет предположить, что фрагменты пиридина располагаются в анти-положении по отношению друг к другу. Этот факт находится в полном согласии с данными по оптимизации структуры соединения, проведенной квантово-химическим методом (Рисунок 1).

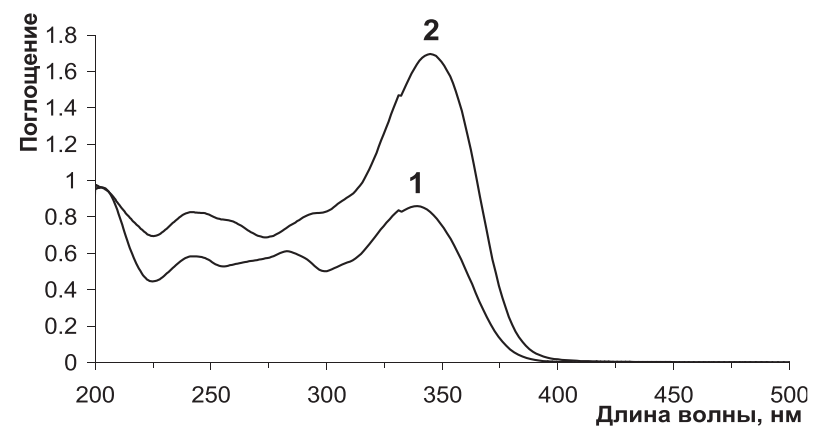

Рисунок 3. Спектры поглощения $E-1\left(C_{1}=3.0 \cdot 10^{-5}\right.$ моль $\left.\pi^{-1}\right)-$ (1) и $E, E-2\left(C_{2}=1.5 \cdot 10^{-5}\right)-(2)$ в $\mathrm{MeCN}, 25^{\circ} \mathrm{C}$.

Электронные спектры поглощения $E-1$ и $E, E-2$ в $\mathrm{MeCN}$ характеризуются наличием интенсивных длинноволновых полос поглощения (ДПП) с максимумами при 339 нм $\left(\varepsilon_{\text {макс }}=28700\right.$ л $\cdot$ моль $\left.^{-1} \cdot \mathrm{cm}^{-1}\right)$ (Рисунок 3 , кривая 1) и $345 \mathrm{Hм}\left(\varepsilon_{\text {макс }}=56500\right.$ л $\cdot$ моль $\left.^{-1} \cdot \mathrm{cm}^{-1}\right)($ Рисунок 3 , кривая 2) a)

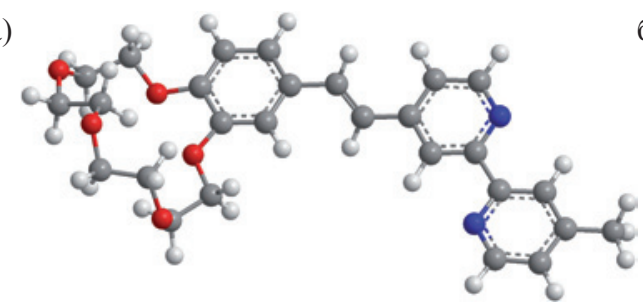

б)

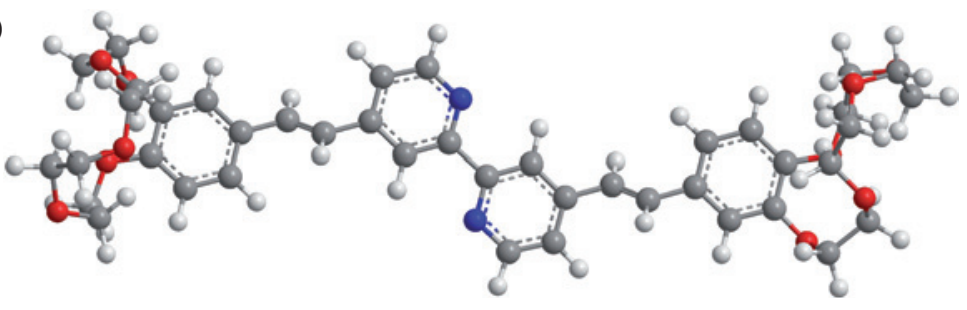

Рисунок 1. Оптимизированная структура молекул $E-1$ (а) и $E, E-2$ (б), РМ6.
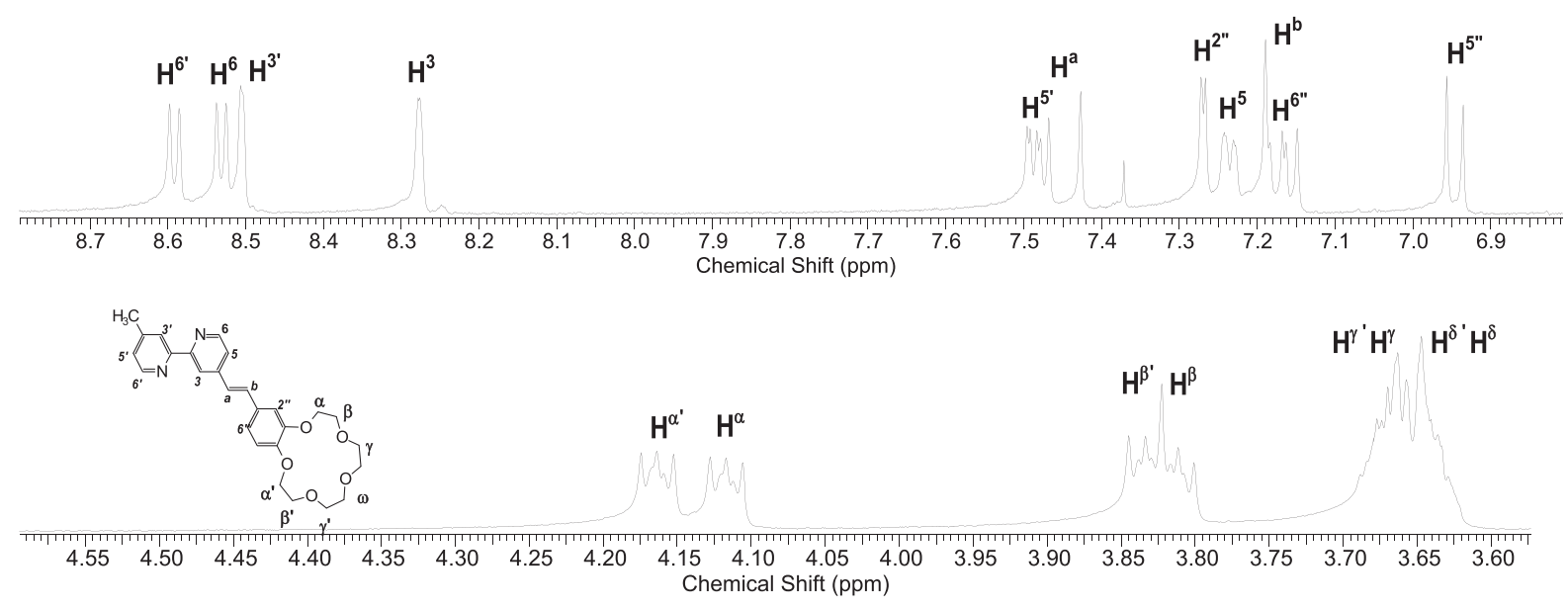

Рисунок 2. ${ }^{1} \mathrm{H}$ ЯМР спектр $E-1$ в $\left(\mathrm{CD}_{3}\right)_{2} \mathrm{SO}\left(25^{\circ} \mathrm{C}\right)$. 
соответственно. ДПП $E, E-2$ сдвинута батохромно на 6 нм по отношению к ДПП моностирилзамещенного аналога $E-\mathbf{1}$, вероятно, из-за электронного влияния друг на друга двух хромофорных частей молекулы. Коэффициент молярного поглощения $E, E-2$ близок к удвоенному коэффициенту молярного поглощения для $E-1$.

\section{Комплексообразование}

Добавление к растворам $E-1$ и $E, E-2\left(C=3.0 \cdot 10^{-5} \mathrm{M}\right.$, $\mathrm{MeCN}$ ) перхлоратов $\mathrm{Zn}^{\mathrm{II}}, \mathrm{Cd}^{\mathrm{II}}$, $\mathrm{Co}^{\mathrm{II}}, \mathrm{Fe}^{\mathrm{II}}, \mathrm{Hg}^{\mathrm{II}}$ или $\mathrm{HClO}_{4}$ приводит к исчезновению ДПП лигандов и появлению новой ДПП, смещенной в красную область спектра, что свидетельствует о комплексообразовании катионов по бипиридиновому фрагменту молекул. Батохромный сдвиг ДПП связан с тем, что появление положительного заряда на бипиридиновом фрагменте облегчает внутримолекулярный перенос заряда от краун-эфирного фрагмента на гетероциклическое ядро лигандов при электронном возбуждении. Взаимодействие $E-\mathbf{1}$ и $E, E-2$ с перхлоратами $\mathrm{Zn}^{\text {II }}$, $\mathrm{Co}^{\mathrm{II}}$, $\mathrm{Cd}^{\mathrm{II}}$ и $\mathrm{Hg}^{\mathrm{II}}$ не ограничивается батохромным сдвигом ДПП лиганда и сопровождается более сложными спектральными изменениями, которые проявляются при высоких концентрациях катионов и могут быть связаны с координацией катионов по краунэфирным фрагментам.

Определение констант устойчивости комплексов $E-1$ и $E, E-2$ с хлорной кислотой и катионами металлов проводилось по данным спектрофотометрического титрования с использованием расчетной программы «SpecFit32”.

При расчете констант устойчивости учитывали возможность образования комплексов согласно следующим схемам:

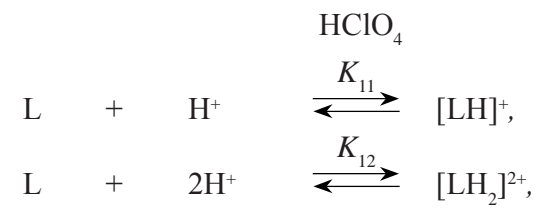

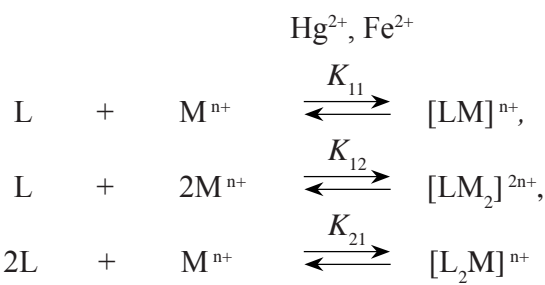

где $\mathrm{L}=E-1$ или $E, E-2, \mathrm{M}^{n+}$ - катион металла.

При взаимодействии молекул $E-1$ и $E, E-2$ с хлорной кислотой образуются моно- и бипротонированные формы соответствующих молекул (Схема 2).

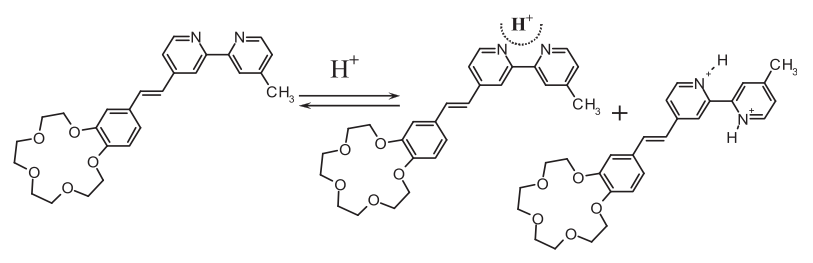

Схема 2.

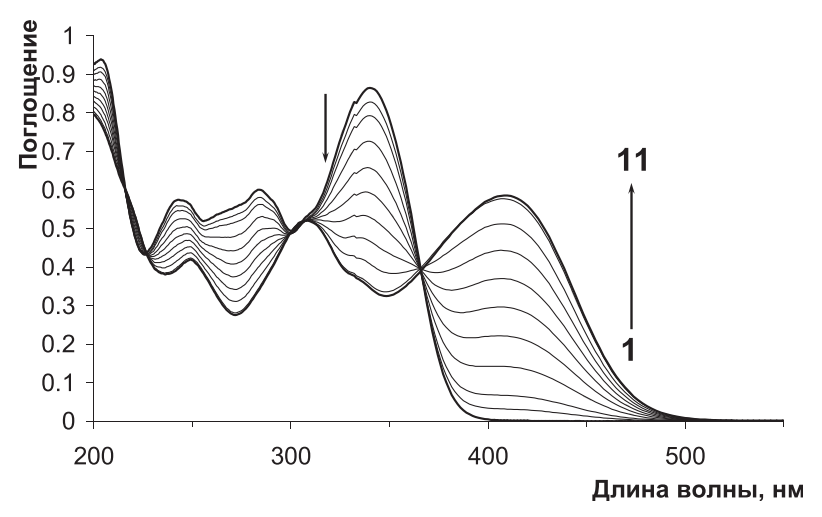

Рисунок 4а. Электронные спектры поглощения $E$-1 при различной концентрации $\mathrm{HClO}_{4}\left(C_{\mathrm{H}^{+}}=0(1)-3.5 \cdot 10^{-5}(11)\right.$, моль $\left.\cdot \pi^{-1}\right)$. Концентрация лиганда постоянна $C_{1}=3.0 \cdot 10^{-5} \mathrm{M}$.

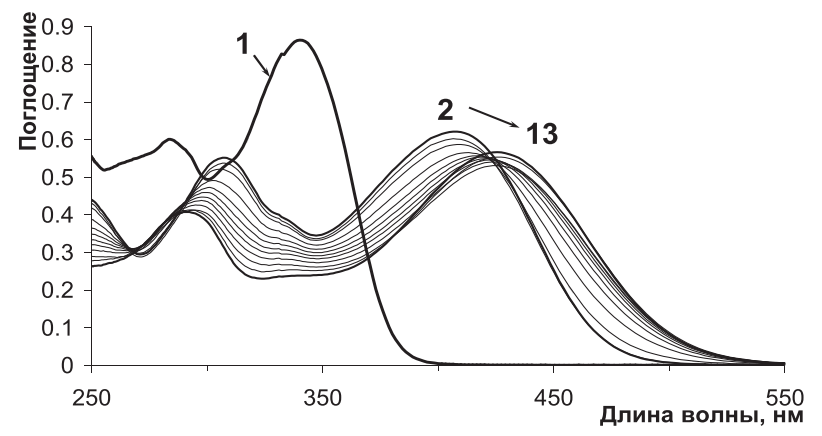

Рисунок 4б. Электронные спектры поглощения $E-1$ при различной концентрации $\mathrm{HClO}_{4}\left(C_{\mathrm{H}^{+}}=0(1), 3.5 \cdot 10^{-5}(2)-\right.$ $8.1 \cdot 10^{-3}(13)$, моль $\left.^{-1}\right)$. Концентрация лиганда постоянна $C_{1}=3.0 \cdot 10^{-5} \mathrm{M}$.

Как и следовало ожидать, присоединение первого протона гораздо эффективнее, чем присоединение второго (логарифмы ступенчатых констант комплексообразования для $E-1$ равны 7.7 и 2.8, соответственно). Электронные спектры поглощения $E-1$ при различной концентрации $\mathrm{HClO}_{4}$ приведены на Рисунках 4a,б.

Вероятно, во взаимодействии с первым протоном принимают участие оба атома азота бипиридинового фрагмента, в то время как присоединению второго протона препятствуют положительный заряд молекулы и необходимость разворота фрагментов пиридина таким образом, чтобы атомы азота были пространственно удалены друг от друга.

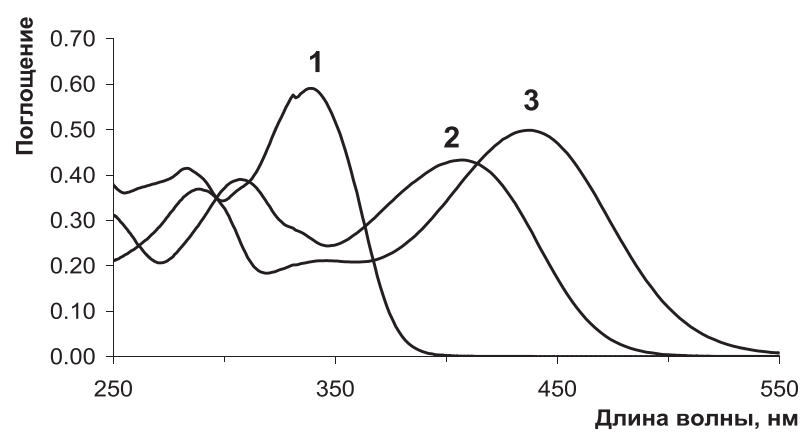

Рисунок 4в. Расчётные спектры поглощения $E-1$ (1) и его протонированных форм $\left[\mathbf{1} \cdot\left(\mathrm{H}^{+}\right)\right](2)$ и $\left[\mathbf{1} \cdot\left(\mathrm{H}^{+}\right)_{2}\right](3)$, вычисленные из данных спектрофотометрического титрования. 
Таблица 1. Константы комплексообразования $E-1$ и $E, E-2$ с катионами $\mathrm{Hg}^{2+}, \mathrm{Fe}^{2+}$ и константы протонирования.

\begin{tabular}{cccccc}
\hline \multirow{2}{*}{$\begin{array}{c}\text { Ком- } \\
\text { плекс }\end{array}$} & $\begin{array}{c}\text { Радиус } \\
\text { катиона, }\end{array}$ & $\begin{array}{c}\text { Ионная } \\
\text { сила, }\end{array}$ & \multicolumn{3}{c}{$\log K_{\text {катион/иганд }}$} \\
\cline { 4 - 6 } & $\AA^{*}$ & моль $\cdot \pi^{-1}$ & $\log K_{12}$ & $\log K_{11}$ & $\log K_{21}$ \\
\hline $\mathbf{1}+\mathrm{Hg}^{2+}$ & 1.10 & $0 \div 7 \cdot 10^{-3}$ & $>16$ & & \\
$\mathbf{2}+\mathrm{Hg}^{2+}$ & 1.10 & $0 \div 2 \cdot 10^{-3}$ & $>16$ & & \\
$\mathbf{1}+\mathrm{Fe}^{2+}$ & 0.75 & $0 \div 3 \cdot 10^{-3}$ & $13.7 \pm 0.2$ & - & - \\
$\mathbf{2}+\mathrm{Fe}^{2+}$ & 0.75 & $0 \div 3 \cdot 10^{-4}$ & $14.9 \pm 0.2$ & - & - \\
$\mathbf{1}+\mathrm{H}^{+}$ & - & $0 \div 4 \cdot 10^{-2}$ & - & $7.7 \pm 0.2$ & $10.47 \pm 0.04$ \\
$\mathbf{2}+\mathrm{H}^{+}$ & - & $0 \div 2 \cdot 10^{-3}$ & - & $7.1 \pm 0.2$ & $11.01 \pm 0.02$ \\
\hline
\end{tabular}

*- По Полингу. ${ }^{[29]}$

Расчётные спектры поглощения $E-\mathbf{1}$ и его протонированных форм $\left[(E-\mathbf{1}) \cdot\left(\mathrm{H}^{+}\right)\right]$и $\left[(E-\mathbf{1}) \cdot\left(\mathrm{H}^{+}\right)_{2}\right]$, вычисленные из данных спектрофотометрического титрования и найденных значений констант комплексообразования, приведены на Рисунке 4в. Значения констант устойчивости комплексов $E-\mathbf{1}$ и $E, E-2$ с ионами $\mathrm{Hg}^{2+}$ и $\mathrm{Fe}^{2+}$, а так же константы протонирования приведены в Таблице 1. Отметим, что максимальный батохромный сдвиг ДПП при протонировании $E-1$ наблюдается для бипротонированного производного. Бипротонированный бипиридил является более сильным акцептором, чем монопротонированный, что облегчает электронный перенос от краун-эфирного фрагмента к протонированному бипиридилу при возбуждении.

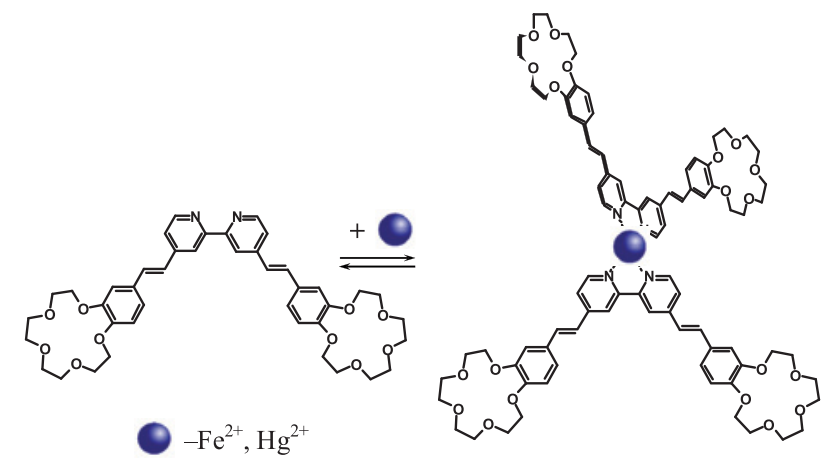

Схема 3.

На основании данных спектрофотометрического титрования (Рисунки 5 и 6) установлено, что с катионами $\mathrm{Hg}^{2+}$ и $\mathrm{Fe}^{2+}$ лиганды $E-1$ и $E, E-2$ образуют комплексы стехиометрии $2: 1$, вероятный состав которых $\left[\mathrm{L}_{2} \cdot\left(\mathrm{Me}^{2+}\right)\right]$ (Схема 3).

Точное определение констант устойчивости комплексов с катионами $\mathrm{Hg}^{2+}$ из данных прямого спектрофотометрического титрования оказалось невозможным из-за их очень высоких значений.

Рассчитанные значения констант комплексообразования $E-1$ и $E, E-2$ с катионами $\mathrm{Fe}^{2+}$ приведены в Таблице 1. Взаимодействие лигандов $E-1$ и $E, E-2$ с перхлоратом $\mathrm{Fe}^{\mathrm{II}}$ сопровождается батохромным сдвигом ДПП и появлением новой полосы поглощения в области 500-600 нм, обусловленной переходом с переносом заряда металл-лиганд, что характерно для комплексов двухвалентного железа с бипиридином или фенантролином. ${ }^{[30,31]}$

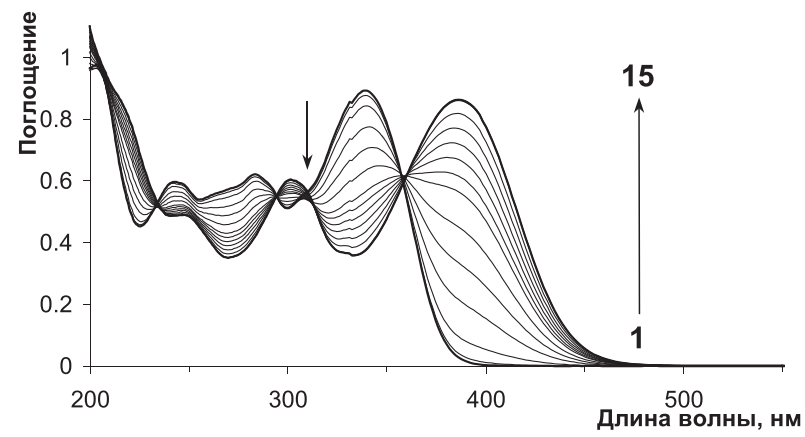

Рисунок 5. Электронные спектры поглощения $E-1$ при различной концентрации перхлората ртути $\left(C_{\mathrm{Hg}^{2+}}=\right.$ от $0(1)$ до $1.7 \cdot 10^{-5}(15)$, моль $\left.^{-1}\right)$. Концентрация лиганда постоянна $C_{1}=3.1 \cdot 10^{-5} \mathrm{M}$.

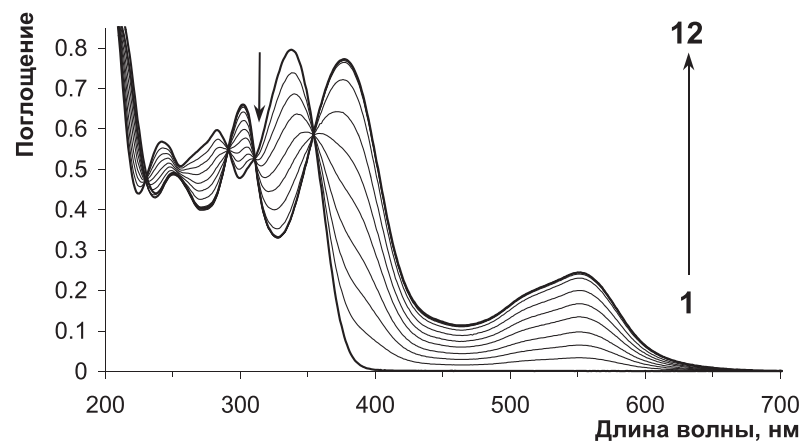

Рисунок 6. Электронные спектры поглощения $E-1$ при различной концентрации перхлората железа $\left(C_{\mathrm{Fe}^{2+}}=\right.$ от $0(1)$ до $3.6 \cdot 10^{-5}(\mathbf{1 2})$, моль $\left.\cdot{ }^{-1}\right)$. Концентрация лиганда постоянна $C_{1}=2.8 \cdot 10^{-5} \mathrm{M}$.

Анализ данных спектрофотометрического титрования растворов $E-1$ и $E, E-2$ в $\mathrm{MeCN}$ перхлоратами $\mathrm{Zn}^{\text {II }}$ (Рисунок 7), $\mathrm{Co}^{\mathrm{II}}$ и $\mathrm{Cd}^{\mathrm{II}}$, полученных при концентрациях соли, не превышающих концентрацию лиганда, показал, что со всеми указанными катионами образуются прочные комплексы состава $\left[\mathrm{L}_{3} \cdot\left(\mathrm{M}^{\mathrm{n}+}\right)\right]$. Вероятная структура таких комплексов типа «клетка» показана на Рисунке 8, а в Таблице 2 приведены рассчитанные значения констант устойчивости комплексов.

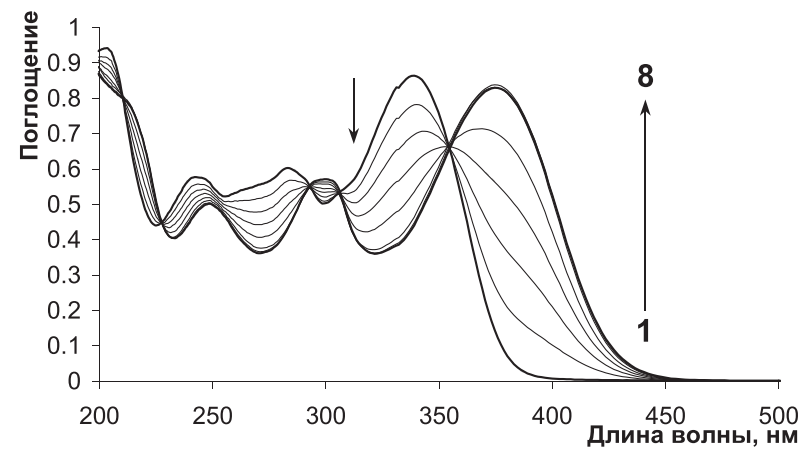

Рисунок 7. Электронные спектры поглощения $E-1$ при различной концентрации перхлората цинка $\left(C_{\mathrm{Zn}^{2+}}=\right.$ от $0(\mathbf{1})$ до $1.4 \cdot 10^{-5}$ $(8),{\text { моль }{ }^{-1}}^{-1}$. Концентрация лиганда постоянна $C_{1}=3.0 \cdot 10^{-5} \mathrm{M}$. 


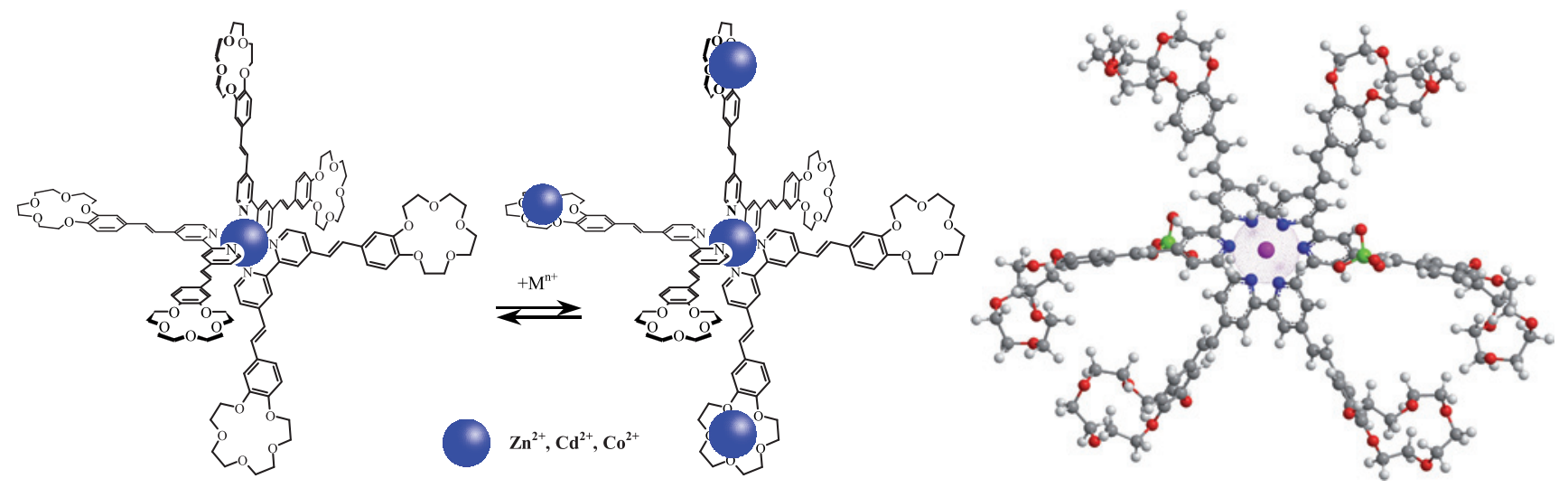

Рисунок 8. Структура комплекса-клетки $E, E-2 \mathrm{c} \mathrm{Zn}{ }^{2+}\left(\mathrm{Cd}^{2+}, \mathrm{Co}^{2+}\right)$ и дальнейшая координация дополнительных катионов по краун-эфирному фрагменту (слева), а также оптимизированная структура комплекса $\left[(E-1) \cdot\left(\mathrm{Zn}^{2+}\right)\right]$, PM6 (справа).

Таблица 2. Константы комплексообразования $E-1$ и $E, E-2$ с катионами $\mathrm{Zn}^{2+}, \mathrm{Cd}^{2+}, \mathrm{Co}^{2+}$.

\begin{tabular}{ccccccc}
\hline \multirow{2}{*}{ Комплекс } & \multirow{2}{*}{$\begin{array}{c}\text { Радиус } \\
\text { катиона, } \AA^{*}\end{array}$} & $\begin{array}{c}\text { Ионная сила, } \\
\text { моль } \pi^{-1}\end{array}$ & $\log K_{13}$ & $\log K_{23}$ & $\log K_{33}$ & $\log K_{34}$ \\
\cline { 4 - 7 } & 0.74 & $0 \div 7 \cdot 10^{-3}$ & $21.1 \pm 0.4$ & $26.4 \pm 0.4$ & $29.3 \pm 0.4$ & $32.4 \pm 0.4$ \\
$\mathbf{1}+\mathrm{Zn}^{2+}$ & 0.74 & $0 \div 7 \cdot 10^{-3}$ & $22.7 \pm 0.6$ & $28.1 \pm 0.2$ & $31.2 \pm 0.2$ & - \\
$\mathbf{2}+\mathrm{Zn}^{2+}$ & 0.97 & $0 \div 1.2 \cdot 10^{-3}$ & $18.5 \pm 0.2$ & $24.3 \pm 0.4$ & $27.7 \pm 0.4$ & - \\
$\mathbf{1}+\mathrm{Cd}^{2+}$ & 0.97 & $0 \div 5 \cdot 10^{-3}$ & $20.1 \pm 0.4$ & $26.0 \pm 0.5$ & $27.6 \pm 0.6$ & - \\
$\mathbf{2}+\mathrm{Cd}^{2+}$ & 0.72 & $0 \div 4 \cdot 10^{-3}$ & $18.8 \pm 0.2$ & $24.7 \pm 0.3$ & - & - \\
$\mathbf{1} \mathrm{Co}^{2+}$ & 0.72 & $0 \div 1.2 \cdot 10^{-2}$ & $20.2 \pm 0.1$ & $25.7 \pm 0.2$ & $27.7 \pm 0.2$ & - \\
$\mathbf{2} \mathbf{C o}^{2+}$ & & & & & & \\
\hline
\end{tabular}

${ }^{*}-$ По Полингу. ${ }^{[29]}$

В случае лиганда $E$-1 состав образующихся комплексов был подтвержден данными масс-спектрометрии (метод ионизации распылением, ИР). При соотношении лиганд:цинк $=3: 1$ в смеси преимущественно присутствует комплекс $\left[(E-1){ }_{3} \cdot\left(\mathrm{Zn}^{2+}\right)\right]($ Рисунок 9).

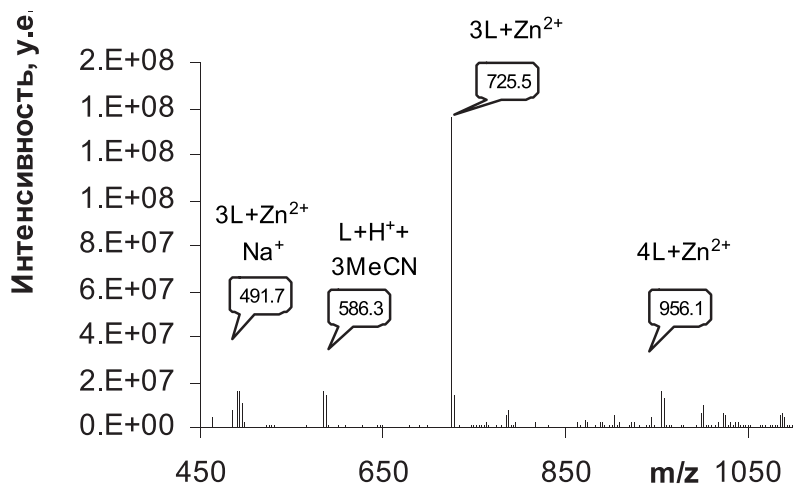

Рисунок 9. ИР-МАСС спектр раствора $E-1$ в присутствии катиона $\mathrm{Zn}^{2+}\left(C_{\mathbf{1}}=3 \cdot 10^{-4}\right.$ моль/л, $C_{\left.\mathrm{Zn}_{(\mathrm{ClO}}\right)_{2}}=1 \cdot 10^{-4}$ моль/л, $\left.\mathrm{MeCN}\right)$.

Для определения состава и устойчивости комплексов, образующихся при большом избытке $\mathrm{Zn}\left(\mathrm{ClO}_{4}\right)_{2}$ (Рисунок 10), $\mathrm{Cd}\left(\mathrm{ClO}_{4}\right)_{2}$ или $\mathrm{Co}\left(\mathrm{ClO}_{4}\right)_{2}$, использовали данные спектрофотометрического титрования при избытке солей и предварительно рассчитанные значения констант устойчивости комплексов $\left[\mathrm{L}_{3} \cdot\left(\mathrm{M}^{\mathrm{n}+}\right)\right]$.

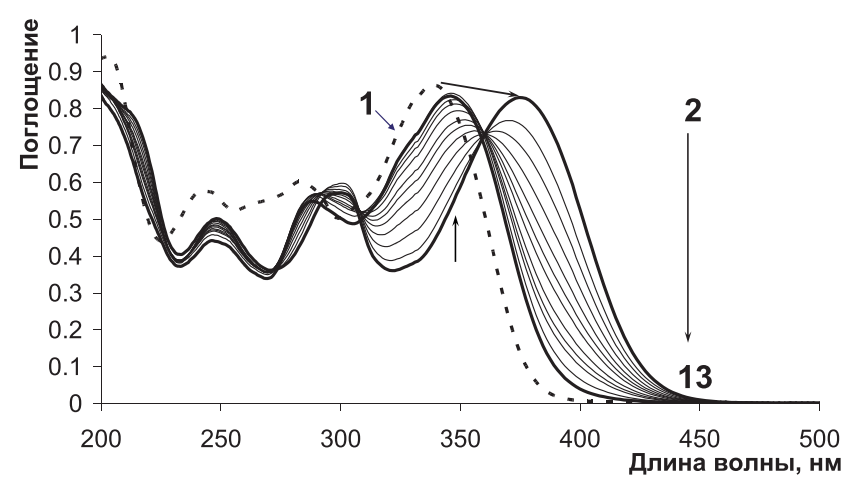

Рисунок 10. Электронные спектры поглощения свободного $E-1(1)$, а так же Е-1 в присутствии перхлората цинка $\left(C_{\mathrm{Zn}^{2+}}=\right.$ от $1.38 \cdot 10^{-5}(2)$ до $7.1 \cdot 10^{-3}(13)$, моль $\left.{ }^{-1}\right)$. Концентрация лиганда постоянна $C_{1}=3.0 \cdot 10^{-5} \mathrm{M}$.

При этом учитывали возможность образования комплексов согласно следующим схемам:

$$
\begin{array}{lllll}
3 \mathrm{~L}+ & \mathrm{M}^{\mathrm{n}+} \underset{K_{31}}{\stackrel{K_{32}}{\rightleftarrows}} & {\left[\mathrm{L}_{3} \mathrm{M}_{1}\right]^{n+},} \\
3 \mathrm{~L}+ & 2 \mathrm{M}^{n+} \stackrel{K_{33}}{\longleftarrow} & {\left[\mathrm{L}_{3} \mathrm{M}_{2}\right]^{2 n+},} \\
3 \mathrm{~L}+ & 3 \mathrm{M}^{\mathrm{n}+} \stackrel{K_{33}}{\longleftarrow} & {\left[\mathrm{L}_{3} \mathrm{M}_{3}\right]^{3 \mathrm{n}},} \\
3 \mathrm{~L}+ & 4 \mathrm{M}^{\mathrm{n}+} \stackrel{K_{34}}{\longleftarrow} & {\left[\mathrm{L}_{3} \mathrm{M}_{4}\right]^{4 \mathrm{n}^{+}}}
\end{array}
$$

где $\mathrm{L}=E-1$ или $E, E-2, \mathrm{M}^{n+}=\mathrm{Zn}^{2+}, \mathrm{Co}^{2+}, \mathrm{Cd}^{2+}$

Макрогетерочииклы / Macroheterocycles 2010 3(4) 201-209 
В результате было обнаружено образование комплексов $\left[\mathrm{L}_{3} \cdot \mathrm{M}_{2}\right]^{4+}$ и $\left[\mathrm{L}_{3} \cdot \mathrm{M}_{3}\right]^{6+}$, содержащих один или два катиона, координированных в полости краун-эфирного фрагмента. Нам не удалось обнаружить комплексы более чем с тремя катионами в краун-эфирах, вероятно из-за невысокой устойчивости таких комплексов.

\section{Спектры флуоресиенции}

Спектры флуоресценции соединений $E-1$ и $E, E-2$ представляют собой широкие бесструктурные полосы с максимумами 447 и 455 нм, соответственно. Значения квантовых выходов флуоресценции приведены в Таблице 3.

Таблица 3. Спектральные характеристики $E-1$ и $E, E-2$ $\left(\lambda_{\text {возб. }}=300\right.$ нм) и их комплексов.

\begin{tabular}{ccccc}
\hline & \multicolumn{2}{c}{ ЭСП } & \multicolumn{2}{c}{ Флуоресценция } \\
\cline { 2 - 5 } Соединение & $\begin{array}{c}\boldsymbol{\lambda}_{\text {макс }} \\
\text { Нм }\end{array}$ & $\begin{array}{c}\boldsymbol{\varepsilon}_{\text {макс }} \cdot 10^{-4}, \\
1 /(\mathrm{M} \cdot \mathrm{cm})\end{array}$ & $\begin{array}{c}\boldsymbol{\lambda}_{\text {макс }} \text { (нм } \\
\text { (сдвиг) }\end{array}$ & $\begin{array}{c}\boldsymbol{\varphi} \text { - квант. выход } \\
\text { флуоресценции }\end{array}$ \\
\hline $\mathbf{1}$ & 339 & 2.90 & 447 & 0.066 \\
$\mathbf{2}$ & 345 & 5.65 & 455 & 0.099 \\
{$\left[\mathbf{1} \cdot\left(\mathrm{H}^{+}\right)\right]$} & 407 & 2.10 & $580(+133)$ & 0.013 \\
{$\left[\mathbf{2} \cdot\left(\mathrm{H}^{+}\right)\right]$} & 410 & 2.81 & $584(+129)$ & 0.011 \\
{$\left[\mathbf{1} \cdot\left(\mathrm{H}^{+}\right)_{2}\right]$} & 427 & 2.34 & $575(+128)$ & 0.0068 \\
{$\left[\mathbf{2} \cdot\left(\mathrm{H}^{+}\right)_{2}\right]$} & 410 & 3.99 & $584(+129)$ & 0.0042 \\
{$\left[\mathbf{1}_{3} \cdot\left(\mathrm{Zn}^{2+}\right)\right]$} & 376 & $2.75^{*}$ & $563(+116)$ & 0.010 \\
{$\left[\mathbf{2}_{3} \cdot\left(\mathrm{Zn}^{2+}\right)\right]$} & 373 & $4.41^{*}$ & $577(+122)$ & 0.0045 \\
{$\left[\mathbf{1}_{3} \cdot\left(\mathrm{Zn}^{2+}\right)_{4}\right]$} & 351 & $2.63^{*}$ & $485(+38)$ & 0.082 \\
{$\left[\mathbf{2}_{3} \cdot\left(\mathrm{Zn}^{2+}\right)_{4}\right]$} & 350 & $3.86^{*}$ & $505(+50)$ & 0.026 \\
{$\left[\mathbf{1}_{3} \cdot\left(\mathrm{Cd}^{2+}\right)\right]$} & 371 & $2.65^{*}$ & $548(+101)$ & $0.014^{* *}$ \\
{$\left[\mathbf{2}_{3} \cdot\left(\mathrm{Cd}^{2+}\right)\right]$} & 372 & $4.14^{*}$ & $560(+105)$ & $0.005^{* *}$ \\
{$\left[\mathbf{1}_{2} \cdot\left(\mathrm{Hg}^{2+}\right)\right]$} & 385 & $2.73^{*}$ & - & $0^{* *}$ \\
{$\left[\mathbf{2}_{2} \cdot\left(\mathrm{Hg}^{2+}\right)\right]$} & 387 & $4.39^{*}$ & - & $0^{* *}$ \\
{$\left[\mathbf{1}_{2} \cdot\left(\mathrm{Fe}^{2+}\right)\right]$} & 377 & $2.79^{*}$ & - & - \\
$-"-$ & 552 & $0.88^{*}$ & - & - \\
{$\left[\mathbf{2}_{2} \cdot\left(\mathrm{Fe}^{2+}\right)\right]$} & 378 & $4.02^{*}$ & - & - \\
$-"-$ & 572 & $1.26^{*}$ & - & - \\
\hline
\end{tabular}

*- Значение экстинкции, деленное на стехиометрический коэффициент лиганда в комплексе.

$* *_{-} \lambda_{\text {возб. }}=313 \mathrm{HM}$.

В присутствии ионов металлов $\left(\mathrm{Zn}^{2+}, \mathrm{Cd}^{2+}, \mathrm{Hg}^{2+}\right)$ и $\mathrm{HClO}_{4}$, способных к координации по центральной гетероциклической части молекул $E-1$ и $E, E-2$, наблюдается тушение флуоресценции (см. например, флуоресценция комплекса $\left[(E-1)_{3} \cdot\left(\mathrm{Zn}^{2+}\right)\right]$ на Рисунке 11, в Таблице 3). Основными процессами безызлучательной релаксации возбужденного состояния рассматриваемых молекул могут быть: а) $E, Z$-фотоизомеризация, б) образование «скрученного состояния» (ТІСТ). ${ }^{[32,33]}$ При координации протона или катиона металла по гетероциклической части возрастает дипольный момент молекулы, что, как известно из исследований аналогичных систем, ${ }^{[34]}$ ведет к преобладанию процесса б) и уменьшению квантового выхода флуоресценции. Для таких катионов как $\mathrm{Hg}^{2+}$ и $\mathrm{Fe}^{2+}$ также возможно предположить перенос заряда с бензокраунэфирной части на центральный катион металла (MLCT) при электронном возбуждении. Протекание такого процесса приводит к полному тушению флуоресценции.

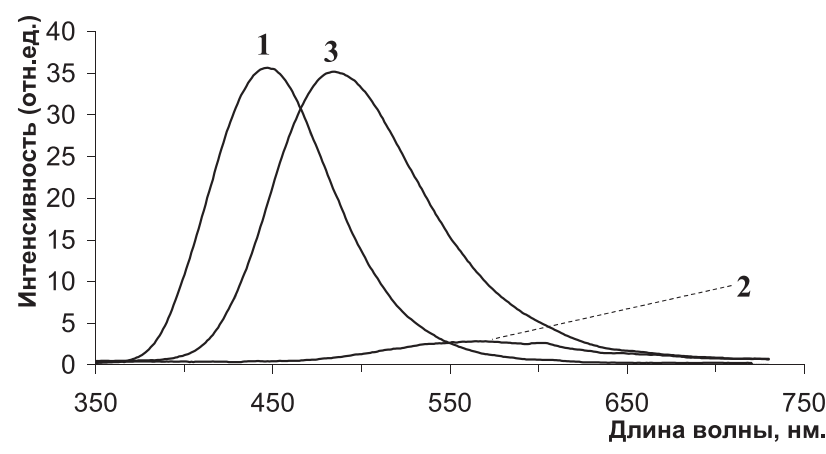

Рисунок 11. Спектры флуоресценции $E-1\left(1, C_{1}=8 \cdot 10^{-6}\right.$ моль $\left.\cdot{ }^{-1}\right)$ и его комплексов с $\mathrm{Zn}^{2+}$ состава $\left[(E-1)_{3} \cdot\left(\mathrm{Zn}^{2+}\right)\right](2)$, $\left[(E-1)_{3} \cdot\left(\mathrm{Zn}^{2+}\right)_{4}\right](3)\left(\lambda_{\text {возб. }}=300 \mathrm{Hм}\right)$.

Следует отметить, что в случае катионов цинка, способных к координации как по центральной гетероциклической части, так и по краун-эфирным фрагментам, интенсивность флуоресценции восстанавливается при больших избытках соли цинка. Наиболее ярко это проявляется для лиганда $E-\mathbf{1}$, содержащего только один краунэфирный фрагмент в молекуле. Образование комплекса $\left[(E-\mathbf{1})_{3} \cdot\left(\mathrm{Zn}^{2+}\right)_{4}\right]$, в котором все краун-эфирные группы заняты катионами цинка, приводит к восстановлению флуоресценции примерно до уровня флуоресценции свободного лиганда (Рисунок 11).

С другой стороны, интенсивность флуоресценции комплекса $\left[(E, E-2)_{3} \cdot\left(\mathrm{Zn}^{2+}\right)_{4}\right]$, в котором три краунэфирные группы остаются незанятыми катионами цинка, почти в четыре раза ниже, чем свободного лиганда. Повидимому, для полного восстановления интенсивности флуоресценции необходимо, чтобы все краун-эфирные группы были заняты катионами, однако, добиться этого оказывается невозможным из-за большого положительного заряда образующегося комплекса.

\section{Фотохимические превращчения}

Облучение раствора $E-\mathbf{1}$ или $E, E-2$ в $\mathrm{MeCN}$ светом с $\lambda_{\text {возб. }}=355$ или $\lambda_{\text {возб. }}=266$ нм приводит к быстрому уменьшению оптической плотности в области ДПП лигандов в результате реакции $E, Z$-фотоизомеризации до достижения фотостационарных состояний. Спектр Z-1 был рассчитан с помощью метода Фишера ${ }^{[35]}$ (Рисунок 12).

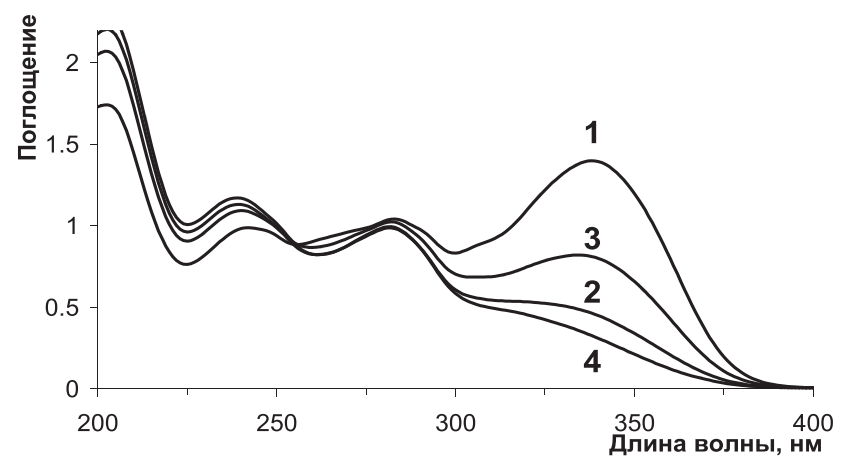

Рисунок 12. Спектры поглощения раствора $E-1$ в $\mathrm{MeCN}\left(C_{1}=\right.$ $5 \cdot 10^{-5}$ моль $\pi^{-1}, 3$ мл) - (1), в фотостационарном состоянии, полученном после облучения светом с длиной волны 355 нм (2) и 266 нм - (3), и спектр $Z$-изомера - (4), рассчитанный по методу Фишера. ${ }^{[35]}$ 
Для определения квантовых выходов прямой и обратной реакции $E, Z$-фотоизомеризации анализировалась экспериментальная зависимость оптической плотности растворов $E-1$ и $E, E-2$ от времени облучения. Расчёт квантовых выходов проводился на основе численного решения соответствующих дифференциальных уравнений:

$$
\begin{array}{r}
\mathrm{A} \stackrel{\text { hи }}{\rightleftarrows} \mathrm{B} \\
\frac{d[A]}{d t}=-\varphi_{A \rightarrow B} \times I_{\text {погл }}^{A}+\varphi_{B \rightarrow A} \times I_{\text {погл }}^{B} \\
\frac{d[B]}{d t}=+\varphi_{A \rightarrow B} \times I_{\text {погл }}^{A}-\varphi_{B \rightarrow A} \times I_{\text {погл }}^{B}
\end{array}
$$

где $\mathrm{I}_{\text {погл }}^{\mathrm{A}}$ и $\mathrm{I}_{\text {погл }}^{\mathrm{B}}-$ количество поглощенных квантов излучения соответствующим веществом А и В за время $d t, \varphi_{A \rightarrow B}$ и $\varphi_{B \rightarrow A}-$ квантовые выходы прямой и обратной реакций соответственно; [A] и [В] - количество молекул соответствующего вещества.

Соединение $E, E-2$ содержит две двойных связи, способных к фотоизомеризации, поэтому метод Фишера неприменим для расчета спектра $Z$-изомера в этом случае. Однако нами было принято допущение, что в фотостационарном состоянии, полученном при облучении раствора $E, E-2$, основными компонентами являются $E, E-2$ и $E, Z-2$, а содержание $Z, Z-2$ мало. В рамках такого допущения, с помощью метода Фишера была произведена оценка спектра поглощения $E, Z-2$ и квантового выхода изомеризации одной $\mathrm{C}=\mathrm{C}$ связи.

Получены значения квантовых выходов $E, Z$ фотоизомеризации: для $(E-1) \varphi_{E \rightarrow Z}=0.423, \varphi_{Z \rightarrow E}=0.369$; для $(E, E-2) \varphi_{E, E \rightarrow E, Z}=0.157, \varphi_{E, Z \rightarrow E, E}=0.199$.

При облучении растворов лигандов в присутствии хлорной кислоты или солей металлов, координирующихся по атомам азота бипиридина, спектральные изменения малы $(E-1)$ или практически отсутствуют $(E, E-2)$. Малые спектральные изменения не позволили рассчитать спектр $Z$-изомера и соотношения квантовых выходов прямой и обратной реакции фотоизомеризации, так же они свидетельствуют о том, что процесс фотохимической трансформации в $Z$-изомер неэффективен, в результате реализуются иные пути релаксации возбужденного состояния, например, внутримолекулярный перенос заряда с образованием ТІСТ-состояния молекул.

Отсутствие $E, Z$ фотоизомеризации наблюдалось для комплексов $\mathrm{Zn}^{2+}$ с лигандами $E-1$ и $E, E-2$ состава $\left[\mathrm{L}_{3} \cdot\left(\mathrm{Zn}^{2+}\right)\right]$. Добавление избытка перхлората цинка приводит к образованию комплекса состава $\left[\mathrm{L}_{3} \cdot\left(\mathrm{Zn}^{2+}\right)_{4}\right]$, в котором катионы цинка связаны как с атомами азота бипиридина, так и с краун-эфирными фрагментами. При этом фотохимические свойства лигандов в составе комплекса становятся близки к свойствам свободного лиганда: растет интенсивность флуоресценции и обнаруживается способность к обратимой реакции $E, Z$-фотоизомеризации.

Спектральные изменения при облучении раствора $\left[(E-1)_{3} \cdot\left(\mathrm{Zn}^{2+}\right)_{4}\right]($ Рисунок 13$)$, также как и квантовые вы- ходы $E$,Z-фотоизомеризации $\left(\varphi_{E \rightarrow Z}=0.343, \varphi_{Z \rightarrow E}=0.402\right)$, близки к свободному лиганду.

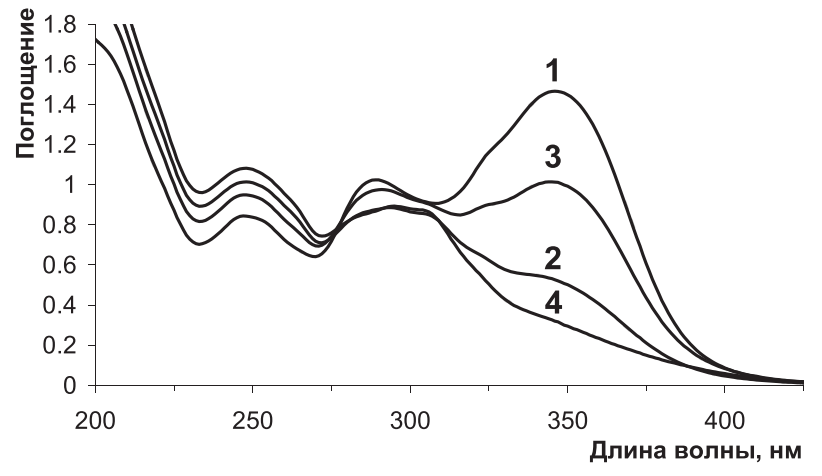

Рисунок 13. Спектры поглощения раствора комплекса $E-1$ с $\mathrm{Zn}^{2+}$ состава $\left[\mathrm{L}_{3} \cdot\left(\mathrm{M}^{\mathrm{n}+}\right)_{4}\right]$ (при избытке $\left.\mathrm{Zn}^{2+}\right)$ в $\mathrm{MeCN}\left(C_{1}=5 \cdot 10^{-5}\right.$ моль $\pi^{-1}, C_{\mathrm{Zn}^{2}+}>5 \cdot 10^{-2}$ моль $\cdot{ }^{-1}, 3$ мл) - (1), в фотостационарном состоянии, полученном после облучения светом с длиной волны 355 нм - (2) и 266 нм - (3), и спектр Z-изомера - (4), рассчитанный по методу Фишера. ${ }^{[35]}$

При облучении растворов комплексов $E-\mathbf{1} E, E-2$ состава $\left[\mathrm{L}_{3} \cdot\left(\mathrm{Cd}^{2+}\right)_{1}\right]$ наблюдается заметное уменьшение интенсивности ДПП, возможно, в результате реакции $E, Z$-фотоизомеризации. Однако, из спектров фотостационарных состояний не удалось рассчитать спектр поглощения Z-изомера, по-видимому, из-за сложности фотохимических процессов, протекающих при облучении кадмиевых комплексов.

Облучение комплексов $E-1$ и $E, E-2$ с $\mathrm{Hg}^{2+}$ приводит к уменьшению поглощения в области ДПП лиганда в результате $E, Z$-фотоизомеризации, причем, равновесие смещено в сторону исходного $E$-изомера. Квантовые выходы $E, Z$-фотоизомеризации для комплекса $E-1 \mathrm{c} \mathrm{Hg}^{2+}$ составляют $\varphi_{E \rightarrow Z}=0.03, \varphi_{Z \rightarrow E}=0.60$, а в случае $E, E-2-$ $\varphi_{Z \rightarrow E}=0.14, \varphi_{E \rightarrow Z}=0.016$.

\section{Выводы}

Таким образом, изучение комплексообразования краунсодержащих 4-моно- и 4,4'-бис(стирил)бипиридинов с катионами металлов различной природы показало, что в случае солей $\mathrm{Hg}^{2+}$ и $\mathrm{Fe}^{2+}$ образуются комплексы хелатного типа, в которых две молекулы лиганда координируются вокруг центрального катиона металла. При взаимодействии лигандов с перхлоратами $\mathrm{Zn}^{\mathrm{II}}, \mathrm{Cd}^{\mathrm{II}}$ и $\mathrm{Co}^{\mathrm{II}}$ образуются комплексы, в которых центральный катион металла капсулируется тремя лигандами за счет координации с атомами азота бипиридиниевого фрагмента молекулы. При увеличении концентрации перхлоратов данных металлов наблюдается взаимодействие катионов с краун-эфирными фрагментами лигандов.

Комплексообразование по гетероциклической части лиганда сопровождается значительным тушением флуореценции лиганда, а также уменьшением квантового выхода обратимой реакции $E, Z$-изомеризации. Дополнительная координация катионов по краун-эфирному фрагменту восстанавливает флуоресценцию и способность к фотоизомеризации. 
Данное исследование демонстрирует подходы к формированию гибридных металлоорганических фоточувствительных ансамблей различной структуры и состава, что представляет несомненный интерес для получения гибридных материалов, важных для технологий органической фотоники.

Благодарность. Работа выполнена при финансовой поддержке Министерства образования и науки РФ (Государственный Контракт № 16.740.11.046) и Российского фонда фундаментальных исследований (проекты № 0903-00047, 09-03-93116, 10-03-93106).

\section{Список литературы}

\section{References}

1. Kaes Ch., Katz A., Hosseini M.W. Chem. Rev. 2000, 100, 3553-3590.

2. Piguet C., Bernardinelli G., Hapfgartner G. Chem. Rev. 1997, 97, 2005-2062.

3. Karunakaran C., Thomas K.R.J., Shunmugasundaram A., Murugesan R. J. Mol. Struct. 2000, 523, 213-221.

4. Karunakaran C., Thomas K.R.J., Shunmugasundaram A., Murugesan R. J. Chem. Crystallogr. 2000, 30, 351-357.

5. Beer P.D., Kcian O., Mortimer R.J., Ridgway Ch., Stradiotto N.R. J. Electroanal. Chem. 1996, 408, 61-66.

6. Wong W.Y., Tsang K.Y., Tam K.H., Lu G.L., Sun C.D. J. Organomet. Chem. 2000, 601, 237-245.

7. Knof U., von Zelewsky A. Angew. Chem., Int. Ed. 1999, 38, 303-322.

8. Belser P., Bernhard S., Jandrasics E., von Zelewsky A., De Cola L., Balzani V. Coord. Chem. Rev. 1997, 159, 1-8.

9. Ward M.D., White C.M., Barigelletti Fr., Armaroli N., Calogero G., Flamigni L. Coord. Chem. Rev. 1998, 171, 481-488.

10. Balzani V., Juris A., Venturi M., Campagna S., Serroni S. Chem. Rev. 1996, 96, 759-833.

11. Kalyanasundaram K., Gätzel M. Coord. Chem. Rev. 1998, 177, 347-414.

12. Baxter S.M., Jones W.E., Danielson E., Worl L., Strouse G., Younathan J., Meyer T.J. Coord. Chem. Rev. 1991, 111, 4771.

13. Venturi M., Credi A., Bolzani V. Coord. Chem. Rev. 1999, 186, 233-256.
14. Fedorova O.A., Gromov S.P., Alfimov M.V. Izv. Akad. Nauk, Ser. Khim. 2001, 11, 1882-1895 (in Russ.) [Russ. Chem. Bull. 2001, 50, 1970-1983].

15. Rurack K., Sczepan M., Spieles M., Resch-Genger U., Retting W. Chem. Phys. Lett. 2000, 320, 87-94.

16. Bricks J.L., Slominskii J.L., Kudinova M.A., Tolmachev A.I., Rurack K., Resch-Genger U., Retting W. J. Photochem. Photobiol., A 2000, 132, 193-208.

17. Demas J.N. Measurement of Photon Yields. In: Optical Radiation Measurements. Academic Press, 1982, Vol. 3, p. 195.

18. Nighswander-Rempel S.P. J. Fluoresc. 2006, 16, 483-485.

19. Nighswander-Rempel S.P., Riesz J., Gilmore J., Meredith P. J. Chem. Phys. 2005, 123, 1-6.

20. Morris J.V., Mahaney M.A., Huber J.R. J. Phys. Chem. 1976, 80, 969-974.

21. Stewart J. J. P. J. Molecular Modeling 2007, 13, 1173-1213.

22. Lindsten G., Wannerstrom O., Thuin B. Acta Chem. Scand., B Org. Chem. Biochem. 1986, 40, 545-554.

23. Marcotte N., Fery-Forgues S., Lavabre D., Marguet S., Pivovarenko V.G. J. Phys. Chem., A 1999, 103, 3163-3170.

24. Xia W.-Sh., Schmehl R.H., Li Ch.-J., Maguc J.T., Luo Ch.-P., Guldi D.M. J. Phys. Chem., B 2002, 106, 833-843.

25. Shinkai S., Ogawa T., Nakaji T., Manabe O. Chem. Commun. 1980, 9, 375-377.

26. Kipriyanov M., Mikhailenko F. Khim. Geterotsikl. Soedin. 1967, 270 (in Russ.).

27. Beer P.D., Kocian O., Mortimer R.J., Ridgway C. Dalton Trans. 1993, 2629-2638.

28. Fedorova O.A., Andryukhina E.N., Mashura M.M., Gromov S.P. Arkivoc 2005, 15, 12-24.

29. Goronovskii I.T., Nazarenko Yu.P., Nekryach E.F. Kratkii Spravochnik Khimika [The Chemist's Brief Handbook] (Kurilenko O.D., Ed.) Kiev: Naukova Dumka, 1974, 991 p. (in Russ.).

30. Grabulosa A., Beley M., Gros P.C. Inorg. Chim. Acta 2010, 363, 1404-1408.

31. Kyeong Jong Lee, Il Yoon, Shim Sung Lee, Bu Yong Lee Bull. Korean Chem. Soc. 2002, 23, 399-403.

32. Vijila C., Ramalingam A., Palanisamy P.K., Masilamani V. Spectrochim. Acta, Part A 2001, 57, 491-497.

33. Sowmiya M., Purkayastha P., Tiwari A.K., S. Syed Jaffer, Subit K. Saha J. Photochem. Photobiol., A 2009, 205, 186-196.

34. Sarkar N., Das K., Nath D.N., Bhattacharyya K. Langmuir 1994, 10, 326-329.

35. Fischer E. J. Phys. Chem. 1967, 71, 3704-3706. 